\title{
Strategies of Hyperglycemia Management among Patients with Diabetic Nephropathy, Renal Impairment, Hypertension and Lipid Disorders
}

\author{
Athanasia K. Papazafiropoulou ${ }^{1 *}$, Marina S. Kardara ${ }^{2}$ and Andreas Melidonis ${ }^{1}$ \\ ${ }^{1}$ Department of Internal Medicine and Diabetes Center, Tzaneio General Hospital of Piraeus, Greece \\ ${ }^{2}$ Health Center of Erymantheia, Achaia, Greece
}

Received: January 09, 2015; Accepted: February 20, 2015; Published: March 05, 2015

*Corresponding author: A. Papazafiropoulou, 1 Zanni \& Afentouli Street, GR-185 36, Piraeus, Greece, Tel: +30-697-996- 9483; E-mail: pathan@ath. forthnet.gr

\begin{abstract}
Diabetic nephropathy, a microvascular complication, usually starts by the development of incipient nephropathy (microalbuminuria), then proteinuria, reduced glomerular filtration rate and finally renal impairment or Chronic Kidney Disease (CKD). CKD if untreated may lead to End Stage Renal Disease (ESRD). Hence, tight glycemic control, and management of hypertension and dyslipidemia is often required to prevent morbidity and mortality. However, this strategy is usually challenging as most of the anti-diabetic therapies need adjustments, modifications or alterations to prevent adverse events and hypoglycemia with CKD. Hence, the aim of the present review is to discuss the up to date existing literature for the management of hyperglycemia with oral agents or insulin among diabetic patients with nephropathy and CKD, while at the same time managing diabetic dyslipidemia and hypertension.
\end{abstract}

Keywords: Type 2 diabetes mellitus, Glomerular filtration rate, Microalbuminuria, End-Stage Renal Disease, Chronic Kidney Disease

\section{Introduction}

Diabetes mellitus is one of the main causes of nephropathy, rising creatinine levels or Chronic Kidney Disease (CKD), and ultimately leading to End-Stage Renal Disease (ESRD) [1,2]. It is important to notice that, in most of cases, Diabetic Kidney Disease or CKD is often present at the time of diabetes diagnosis [3]. The earliest clinical manifestation of diabetic nephropathy and CKD is Microalbuminuria (MA), also known as incipient nephropathy, which is defined as $\geq 30 \mathrm{mg}$ per 24 hours of albumin excretion $[4,5]$. Annual testing for MA in diabetic subjects is established by the American Diabetes Association's guidelines [4] with 3 methods of screening: measurement of albumin-to-creatinine ratio in a random spot urine collection, 24-hour collection with creatinine allowing for simultaneous measurement of creatinine clearance, and timed collection of urine.

However, management of diabetic subjects with CKD still remains a challenge to diabetologists since pharmaceutical agent's metabolism is usually affected by serum creatinine levels and serious adverse events, such as hypoglycemia and hyperkalemia, are usually present with these patients [5]. Therefore, the aim of the present review was to summarize the existing literature data regarding simultaneous management of subjects with Type 2 Diabetes Mellitus (T2DM) with nephropathy, CKD, hypertension with co-existing diabetic dyslipidemia [6].

Towards this aim, we performed a systematic search in the PubMed and EMBASE databases using the terms 'Type 2 Diabetes Mellitus', 'Glomerular Filtration Rate', 'Microalbuminuria', 'EndStage Renal Disease' And 'Chronic Kidney Disease' alone and in combination to retrieve available data.

\section{Lifestyle Modifications}

\section{Smoking}

The role of smoking in the development and progression ofCKD is well established [7,8]. A lot of studies have showed that smoker diabetics have higher prevalence of MA, macroalbuminuria and reduced GFR compared with their nonsmoking counterparts $[7,8]$. On the other hand, smoking cessation has been showed to be effective at preventing progression of early nephropathy in subjects with T2DM [9]. Therefore, it is of great importance the recommendation of smoking cessation to all diabetic subjects with CKD according to the current guidelines [7].

\section{Weight loss}

Obesity is independently related to increased CKD risk in diabetics [10]. Weight loss has been shown to reduce proteinuria and MA while it stabilizes kidney function in subjects with T2DM [11]. These findings are related to the observed reduction in Blood Pressure (BP) in these patients [11]. The National Kidney Foundation recommends a target Body Mass Index (BMI) of 18.5 - $24.9 \mathrm{~kg} / \mathrm{m}^{2}$ for diabetics with CKD [2]. Weight management programs should comprise dietary restriction and increased physical activity, coupled with appropriate counseling [12]. Bariatric surgery should be considered only for patients with T2DM and BMI > $35 \mathrm{~kg} / \mathrm{m}^{2}$ [12]. 


\section{Dietary modifications}

Protein restriction has been shown to slow the progression of albuminuria, the decline in GFR, and the development of ESRD $[2,12]$. Patients with early-stage CKD should be advised to limit their protein intake to $0.8 \mathrm{~g} / \mathrm{kg}$ body weight per day; the target for those with late-stage CKD is $0.8 \mathrm{~g} / \mathrm{kg}$ or lower per day [12]. The reduction of sodium intake $(\leq 2.4 \mathrm{~g} / \mathrm{d}$ of sodium or $\leq 6 \mathrm{~g}$ of salt) and alcohol consumption ( $\leq 2$ drinks/day for most men or 1 drink/day in women and lighter-weight individuals) will have a positive effect on BP [13]. Dietary changes to improve diabetic dyslipidemia should comprise reductions in saturated fat, trans fat, and cholesterol intake, together with increases in omega-3 fatty acids, viscous fiber, and plant stanols/sterols [12].

\section{T2DM Pharmacological Treatment}

\section{Biguanides}

Metformin is globally accepted as the first choice in all therapeutic algorithms for diabetic subjects management. It is known that metformin is eliminated by the kidneys [14] and, therefore, reduction of GFR results to a reduction in the elimination of metformin by the kidneys increasing the risk of adverse events [15]. One of these is lactic acidosis, a rare but very dangerous side effect of metformin [16]. Risk factors for lactic acidosis by metformin are heart failure, advanced age, alcohol consumption and iodinated radiographic contrast media [14]. In the latter case, metformin should be stopped 2 days before the use of iodinated radiographic contrast media and can be given to patient only after renal function has returned to a normal baseline $[17,18]$. According to the current guidelines, metformin should not be administered in diabetic patients with creatinine levels above $1.4 \mathrm{mg} / \mathrm{dl}$ in women and $1.5 \mathrm{mg} / \mathrm{dl}$ in men.

\section{Sulfonylureas}

Second-generation sulfonylureas that are used in daily clinical practice are glipizide, glyburide, glimepiride and gliclazide. Glipizide is metabolized by the liver $[19,20]$ and, therefore, reduction of GFR does not affect its dose in CKD subjects [21] Glyburide is, also, metabolized by the liver $[19,22,23]$, but its metabolites have hypoglycemic activity and, therefore, glyburide should use with caution according to the stage of CKD [2325]. Glimepiride is, also, metabolized by the liver [23-26], but hypoglycemia has been reported with the use of glimepiride in CKD subjects and, therefore glimepiride should be used with caution in CKD subjects [19,27]. Its use is safe in GFR $\geq 60 \mathrm{ml} / \mathrm{min}$ and with a reduced dose of up to $30 \mathrm{ml} / \mathrm{min}$. Gliclazide causes less hypoglycemia than other sulfonylureas and is safe for GFR levels $\geq 30 \mathrm{ml} / \mathrm{min}$.

\section{Meglitinides}

Repaglinide is metabolized by the liver $[28,29]$. However, its elimination is diminished in subjects with reduced GFR [3032] leading to the need for dose adjustment [32]. However, in CKD stages 4 and 5repaglinide can be used without dose adjustment. Nateglinide, despite its liver metabolism [33], can cause hypoglycemia in subjects with reduced GFR because of the reduction of plasma protein binding [34]. Therefore in stage 4 we adjust the dose of nateglinide because of the risk of hypoglycemia $[35,36]$ while in CKD stage 5 we avoid its use.

\section{Thiazolidinediones}

Pioglitazone is hepatically metabolized, forming several metabolites that are not accumulated in CKD subjects [19,37]. The most worrisome side effect of pioglitazone is edema that can worst pre-exisitng heart failure in CKD subjects [38,39]. Pioglitazone does not need dose adjustment in CKD subjects. However, it should be used with caution because of risk of congestive heart failure [38,39]. The use of pioglitazone in CKD subjects is in decreased dose (15 mg once a day).

\section{Alpha-glucosidase inhibitors}

Acarbose is an alpha-glucosidase inhibitor that is absorbed from the gastrointestinal tract [19]. Its metabolites are secreted by the urine and in subjects with impaired renal function its elimination is diminished [19]. Therefore, in subjects with CKD stages 4 and 5 should not be used [19].

\section{GLP-1 analogues}

Exenatide, the first GLP-1 analogue used for the treatment of diabetes, is eliminated mainly by the kidneys $[40,41]$. Reduction in GFR has as a result an elevation in drug's half-life time [40]. Therefore, for GFR's levels between 30 and $50 \mathrm{ml} / \mathrm{min}$ a reduction of drug's dosage is recommended while for GFR's levels lower than $30 \mathrm{ml} / \mathrm{min}$ exenatide should not be used [40, 41]. Regarding liraglutide, another GLP-1 analogue [42,43], a recent meta-analysis showed that mild renal impairment had no effect on the efficacy and safety of liraglutide [44]. However, since there are not large clinical studies in patients with GFR $<60 \mathrm{~mL} /$ min liraglutide cannot be used under these cut off point.

\section{DPP-4 inhibitors}

Sitagliptin, is mainly eliminated by the kidneys [45]. In subjects with moderate kidney disease sitagliptin can be used in dosage of $50 \mathrm{mg}$ while for more severe kidney disease sitagliptin can be used in dosage of $25 \mathrm{mg}[46,47]$. Saxagliptin is mainly metabolized by the liver by cytochrome P450 3A4/5 [48]. According to recent data a dosage of $2.5 \mathrm{mg}$ of saxagliptin is suggested for subjects with GFR $<50 \mathrm{ml} / \mathrm{min}$ [48]. Vildagliptin, another oral DPP-4 inhibitor should be used with caution in subjects with CKD [49,50]. A 24-week study including subjects with T2DM and moderate or severe renal impairment, vildagliptin (50 mg once-daily) added to ongoing anti-diabetic therapy had a safety profile similar to placebo [51]. In patients with CKD stage $\geq 3$, vildagliptin needs dose adjustment. For GFR $<50 \mathrm{mg} / \mathrm{mL}$ the dose of vildagliptin is $50 \mathrm{mg}$. Linagliptin is the newer oral DPP-4 inhibitor. Renal impairment has only a minor effect on linagliptin pharmacokinetics. Consequently, there is no need for adjusting the linagliptin dose in diabetics with CKD [52].

\section{Insulin}

Insulin is metabolized by the kidneys [53]. Reduction of GFR has as a result a reduction to exogenous insulin clearance and 
its plasma accumulation [54-57]. For GFR levels between 50 and $10 \mathrm{ml} / \mathrm{min}$ insulin dosage should be reduced by half [19]. Even more, subjects on dialysis have less need for exogenous insulin [57]. Rapid-acting insulin analogs are preferred for subjects with CKD since their half-life time is almost unchanged in subjects with CKD because of the lower risk of hypoglycemia [58]. Long-acting insulin, glargine and detemir, are acceptable in CKD subjects [58]

\section{Antihypertensive Treatment}

\section{Diuretics}

Thiazide diuretics are used in CKD stage 1-4 while loop diuretics are used in CKD stage 4-5 [59]. Although a large dose of a thiazide diuretic will initiate a diuresis in subjects with mild renal insufficiency, the response in subjects with GFR $<50 \mathrm{ml}$ / min is more limited. In subjects receiving fixed-dose combination antihypertensive therapy containing a thiazide diuretic, a loop diuretic should be considered when GFR values drop to below $50 \mathrm{ml} / \mathrm{min}$ and $\mathrm{BP}$ control is inadequate and/or edema is present [60]. Fixed-dose combination antihypertensive therapies with a thiazide diuretic component do not require change in the non edematous CKD subjects with good BP control.

Potassium-sparing diuretics are generally used cautiously in CKD subjects because of the risk of hyperkalemia. Dosage adjustment for aldosterone receptor antagonists is based on the level of renal function and by the possibility of hyperkalemia [61]. Spironolactone has a prolonged potassium- sparing effect, which should be accounted for when it is prescribed. Eplerenone has less significant effects in serum potassium [61]

\section{Alpha adrenergic antagonists}

Dose adjustment of alpha adrenergic antagonists in CKD subjects is not required. These compounds are used in the hypertensive CKD subjects as useful add-on compounds in the setting of resistant hypertension [62]. Adrenergic antagonists have a tendency to increase plasma volume in subjects with CKD and therefore, these drugs should be used with diuretic therapy [63].

\section{Central $\alpha$-agonists}

Central $\alpha$-agonists are still used in the hypertensive CKD subjects. Clonidine undergoes modest renal clearance and its plasma half-life is somewhat prolonged in CKD subjects [64] However, there are no specific recommendations for dosage adjustment in this population [64].

\section{Beta blockers}

Beta blockers are commonly utilized drugs in CKD subjects either for the treatment of hypertension and/or for their cardioprotective effects [65-67]. The BP-lowering effect of beta blockers is somewhat unpredictable in CKD subjects unless combined with a diuretic [65]. If side effects occur, one option is to continue the beta blocker with dose reduction and the other to convert to a hepatically-cleared beta blocker.

\section{Calcium-channel blockers}

Calcium-Channel Blockers (CCBs) are commonly used drugs in CKD subjects because of the consistency of their BP lowering response and the absence of dose adjustment in these subjects [68]. Dihydropyridine and non-dihydropyridine CCBs (Verapamil and Diltiazem), reduce BP similarly in CKD subjects. The addition of a CCB to other drug classes, including diuretics, produces a better result to BP control [69].

Greater reductions in proteinuria have been seen with nondihydropyridine CCBs such as Verapamil and Diltiazem, despite BP reduction comparable to those seen with dihydropyridine CCBs [70]. When given in combination with either an ACE inhibitor or an Angiotensin Receptor Blocker (ARB), the treatment advantage of a non-dihydropyridine versus a dihydropyridine CCB becomes less important [71]. The side effects of CCB are more pronounced in CKD subjects. CKD subjects tend to be constipated, a process aggravated by Verapamil. In addition, CCBs can produce a vasodilatory peripheral edema, which is a type of edema without weight gain [72].

\section{Angiotensin-converting enzyme inhibitors}

Most ACE inhibitors are exclusively renally cleared with varying degrees of filtration and tubular secretion [73]. The BP-lowering effect of ACE inhibitors is generally less in volume expanded forms of hypertension, as in the case of CKD. In CKD subjects, the addition of a diuretic to an ACE inhibitor is frequently necessary to lower BP. The major adverse events of ACE inhibitor accumulation are prolonged BP reduction, an extended decrease in GFR, and/or an unacceptable increase in serum potassium concentration. These adverse events do not mandate permanent discontinuation of the ACE inhibitor and in most cases ACE inhibitor can be cautiously reintroduced [74]. If the ACE inhibitor effect, BP reduction, or the side effect, drop in GFR and/or hyperkalemia, occur, then the dose should be reduced if not temporarily discontinued. If hyperkalemia occurs with an ACE inhibitor, a reduced dose or use of a non-accumulating ACE inhibitor can be considered. If hyperkalemia persists and ACE inhibition remains vital (congestive heart failure), a potassiumbinding resin can be used [74].

\section{Angiotensin receptor blockers}

Like ACE inhibitors, ARB monotherapy is generally less efficacious in the treatment of CKD-related hypertension and typically requires the addition of a diuretic to maximize its BP-lowering effect. These drugs undergo significant hepatic elimination with the exception of candesartan, olmesartan, and one metabolite of losartan, which are $40 \%, 60 \%$, and $50 \%$ hepatically-cleared, respectively [75]. Like ACE inhibitors, the dose of an ARB given to a CKD subject should be adjusted to achieve a specific BP goal and thereafter empirically for any additional antiproteinuric effect [76].

\section{Treatment of Dyslipidemia}

Statins are generally well tolerated at moderate doses in subjects with CKD stages 1-2 [77]. Safety issues and dose adjustment become important in more advanced stages of CKD (stages 3-5), as adverse events are commonly dose related and due to increased blood concentration of the compound. Statins 
with minimal renal excretion should be the drug of choice (Atorvastatin, Fluvastatin, and Pitavastatin) [77].

Growing evidence indicates that fibrates increase serum creatinine and homocysteine, both being established cardiovascular risk factors [77]. Effects of fenofibrate are more pronounced than those of gemfibrozil [77]. As fibrates have no effect on creatinine excretion into urine, the estimation of GFR is hampered by the rise of creatinine [77]. Fenofibrate is also nondialyzable and should not be used in subjects with GFR $<50 \mathrm{ml} /$ min. The dose of gemfibrozil is recommended to be reduced to $600 \mathrm{mg} /$ day if GFR is $<60 \mathrm{ml} / \mathrm{min}$ and avoided if GFR is $<15 \mathrm{ml} /$ $\min [77]$.

Recently the availability of prescription brand n-3 fatty acids provides an option to lower triglycerides in subjects with mixed dyslipidemia [77].

\section{Statins in Subjects with CKD}

Some dosage modifications for some of the statins need to be carried out as GFR levels fall. Atorvastatin and its metabolites are excreted mostly in bile, and urinary excretion is low, so dosages do not have to be modified as GFR levels fall [78]. Atorvastatin can be given in dosages up to $80 \mathrm{mg}$ per day in subjects who are on both hemodialysis and Chronic Ambulatory Peritoneal Dialysis (CAPD) [78]. In subjects who are on hemodialysis, the dosage can be given before or after dialysis [78].

Fluvastatin is almost completely metabolized by the liver with $5 \%$ excreted in the urine [78]. Therefore, it also can be given in dosages up to $80 \mathrm{mg}$ per day even in subjects who are on hemodialysis and CAPD [78].

Data on pravastatin are less certain with respect to declining GFR levels, and pravastatin and its active metabolites may accumulate [78]. Therefore, it has been recommended that dosages of pravastatin start at $10 \mathrm{mg}$ per day and higher doses be used cautiously when the GFR is $<50 \mathrm{ml} / \mathrm{min}$ [78]. However, as noted in the Pravastatin Pooling Project, $40 \mathrm{mg}$ was used down to $30 \mathrm{ml} / \mathrm{min}$, and there were no adverse effects from this [79].

Simvastatin is almost completely metabolized by the liver [78]. In the First United Kingdom Heart and Renal Protection (UKHARP-I) study, 448 subjects with CKD (242 predialysis subjects with serum creatinine level $>1.7 \mathrm{mg} / \mathrm{dl}, 73$ on hemodialysis and 133 with a transplant) were randomly assigned to simvastatin $20 \mathrm{mg}$ or placebo for 1 year. Low Density Lipoprotein (LDL)cholesterol levels were lowered by 27,20 , and $20 \mathrm{mg} / \mathrm{dl}$ in these three groups without any significant increase in the adverse effects of muscle pain, muscle weakness, rhabdomyolysis, or elevation of creatinine phosphokinase or alanine aminotransferase [80]. In the HPS study, subjects were treated with $40 \mathrm{mg}$ per day in many subjects with CKD stage 3 without an excess risk for rhabdomyolysis [81].

Rosuvastatin is $90 \%$ excreted unchanged in the feces and only $10 \%$ in urine [79]. When the GFR is $<30 \mathrm{ml} / \mathrm{min}$, it has been found to accumulate, so it should not be given at a dosage of $>10$ mg with this degree of CKD [79].
Ezetimibe is being used with increasing frequency in many patients to augment the LDL-cholesterol lowering effects of statins [82]. The recent Second United Kingdom Heart and Renal Protection (UK-HARP-II) study found in a randomized, controlled study that $10 \mathrm{mg}$ of ezetimibe added to $20 \mathrm{mg}$ of simvastatin in 203 subjects with CKD (152 predialysis subjects with serum creatinine $>1.7 \mathrm{mg} / \mathrm{dl}, 18$ on peritoneal dialysis and 33 on hemodialysis) resulted in an incremental $21 \%$ reduction of LDL-cholesterol levels over simvastatin alone without an excess risk for abnormal liver or muscle function tests or other adverse events [83]. Therefore, no dosage adjustment of ezetimibe is needed in subjects with renal insufficiency $[82,83]$.

Bile acid sequestrants, such as cholestyramine, also can be used, and the dosage does not have to be altered with decreases in GFR [84]. When the GFR falls to $<30 \mathrm{ml} / \mathrm{min}$, it seems that atorvastatin and fluvastatin are preferred because no dosage adjustments need to be made.

Gemfibrozil dosing does not have to be adjusted even for CKD stage 4 [85]; in CAPD subjects, dosages of $>600 \mathrm{mg}$ per day have been associated with an increased frequency of CPK elevations [86]. However, fenofibrate dosages should be reduced by one third in CKD stage 2, by an additional one third in CKD stages 3 and 4, and avoided in CKD stage 5 [84]. Combination of fibrates and statins probably best are avoided in subjects with CKD to avoid the complication of rhabdomyolysis $[84,87]$. Nicotinic acid dosages do not have to be adjusted until CKD stage 5, when the dose should be reduced by $50 \%$ [84].

In conclusion, diabetic subjects with CKD are a high cardiovascular risk population that needs intensive treatment aiming at diabetes, BP and lipids control. However, presence of diabetic nephropathy influences therapeutic choices leading either to dose adjustment or to contradiction of agents used for the treatment of diabetes, hypertension and lipids disorders.

\section{Recommendations}

In view of above mentioned facts, it is recommended that tight glycemic control is essential to prevent diabetes complications. Hypertension and dyslipidemia management is essential as well while managing diabetes. In case of renal impairment or rising creatinine levels above $1.5 \mathrm{mg} / \mathrm{dl}$ (CKD), it is highly recommended to discontinue metformin, sulfonylureas, or any anti-diabetic agents to avoid further complications or hypoglycemia. In such cases, replacement of oral agents with insulin therapy is advised. Similarly, patients already on insulin and who recently demonstrated renal impairment (CKD), insulin dosages should be reduced according to the results of Self-Monitoring Blood Glucose (SMBG) to prevent hypoglycemia.

\section{References}

1. Molitch ME, DeFronzo RA, Franz MJ, Keane WF, Mogensen CE, Parving $\mathrm{HH}$, et al. American Diabetes Association. Nephropathy in Diabetes. Diabetes Care. 2004; 27(suppl 1):S79-S83. doi: 10.2337/ diacare.27.2007.S79.

2. KDOQI. KDOQI clinical practice guidelines and clinical practice recommendations for diabetes and chronic kidney disease. Am J Kidney Dis. 2007; 49(2 Suppl 2):S12-154. 
3. Plantinga LC, Crews DC, Coresh J, Miller ER 3rd, Saran R, Yee J, et al. Prevalence of chronic kidney disease in US adults with undiagnosed diabetes or prediabetes. Clin J Am Soc Nephrol. 2010; 5(4):673-682. doi: 10.2215/CJN.07891109.

4. Molitch ME, DeFronzo RA, Franz MJ, Keane WF, Mogensen CE, Parving $\mathrm{HH}$, et al. Position statement: diabetic nephropathy. Diabetes Care 2004; 27(suppl 1): S79-S83. doi: 10.2337/diacare.27.2007.S79.

5. Winter S, Jernigan V. Vascular disease risk markers in diabetes: monitoring and intervention. Nurse Pract. 2000; 25(6 Pt 1):40, 43-6 49 passim; quiz 65-7.

6. Laliberté F, Bookhart BK, Vekeman F, Corral M, Duh MS, Bailey RA, et al. Direct all-cause health care costs associated with chronic kidney disease in patients with diabetes and hypertension: a managed care perspective. J Manag Care Pharm. 2009; 15(4):312-322.

7. Haire-Joshu D, Glasgow RE, Tibbs TL. Smoking and diabetes. Diabetes Care. 1999; 22(11):1887-1898.

8. Cignarelli M, Lamacchia O, Di Paolo S, Gesualdo L. Cigarette smoking and kidney dysfunction in diabetes mellitus. J Nephrol. 2008, 21(2):180-189.

9. Chuahirun T, Simoni J, Hudson C, Seipel T, Khanna A, Harrist RB, et al. Cigarette smoking exacerbates and its cessation ameliorates renal injury in type 2 diabetes. Am J Med Sci. 2004; 327(2):57-67.

10. Eknoyan G. Obesity, diabetes, and chronic kidney disease. Curr Diab Rep. 2007; 7(6):449-453.

11. Afshinnia F, Wilt TJ, Duval S, Esmaeili A, Ibrahim HN. Weight loss and proteinuria: systematic review of clinical trials and comparative cohorts. Nephrol Dial Transplant. 2010; 25(4):1173-83. doi: 10.1093/ ndt/gfp640.

12. American Diabetes Association. Standards of medical care in diabetes-2010. Diabetes Care 2010; 33(suppl 1): S11-S61. doi $10.2337 / \mathrm{dc} 10-\mathrm{S} 011$

13. Bakris GL, Sowers JR; American Society of Hypertension Writing Group. Treatment of hypertension in patients with diabetes-an update. J Am SocHypertens 2010; 4(2): 62-67.

14. Melchior WR, Jaber LA. Metformin: an antihyperglycemic agent for treatment of type II diabetes. Ann Pharmacother. 1996; 30(2):158164.

15. Graham GG, Punt J, Arora M, Day RO, Doogue MP, Duong JK, et al Clinical pharmacokinetics of metformin. Clin Pharmacokinet. 2011; 50(2):81-98. doi: 10.2165/11534750-000000000-00000.

16. Misbin RI. The phantom of lactic acidosis due to metformin in patients with diabetes. Diabetes Care. 2004; 27(7):1791-1793.

17. Lalau JD, Andrejak M, Moriniere P, Coevoet B, Debussche X, Westeel $\mathrm{PF}$, et al. Hemodialysis in the treatment of lactic acidosis in diabetics treated by metformin: a study of metformin elimination. Int J Clin Pharmacol Ther Toxicol. 1989; 27(6):285-288.

18. Seidowsky A, Nseir S, Houdret N, Fourrier F. Metformin-associated lactic acidosis: a prognostic and therapeutic study. Crit Care Med 2009; 37(7):2191-2196. doi: 10.1097/CCM.0b013e3181a02490.

19. Charpentier G, Riveline JP, Varroud-Vial M. Management of drugs affecting blood glucose in diabetic patients with renal failure. Diabetes Metab. 2000; 26 Suppl 4:73-85

20. Gerich JE. Oral hypoglycemic agents. N Engl J Med. 1989; 321(18):12311245 .

21. Balant L, Zahnd G, Gorgia A, Schwarz R, Fabre J. Pharmacokinetics of glipizide in man: influence of renal insufficiency. Diabetologia. 1973:331-338.

22. FeldmanJM.Glyburide: asecond-generation sulfonylureahypoglycemic agent. History, chemistry, metabolism, pharmacokinetics, clinical use and adverse effects. Pharmacotherapy. 1985; 5(2):43-62.

23. Pearson JG, Antal EJ, Raehl CL, Gorsch HK, Craig WA, Albert KS, et al. Pharmacokinetic disposition of 14C-glyburide in patients with varying renal function. Clin Pharmacol Ther. 1986; 39(3):318-324

24. Krepinsky J, Ingram AJ, Clase CM. Prolonged sulfonylurea-induced hypoglycemia in diabetic patients with end-stage renal disease. Am J Kidney Dis. 2000; 35(3):500-505

25. Rydberg T, Jonsson A, Roder M, Melander A. Hypoglycemic activity of glyburide (glibenclamide) metabolites in humans. Diabetes Care. 1994; 17(9):1026-1030.

26. Rosenkranz B, Profozic V, Metelko Z, Mrzljak V, Lange C, Malerczyk V. Pharmacokinetics and safety of glimepiride at clinically effective doses in diabetic patients with renal impairment. Diabetologia. 1996; 39(12):1617-1624.

27. Holstein A, Egberts EH. Risk of hypoglycaemia with oral antidiabetic agents in patients with Type 2 diabetes. Exp Clin Endocrinol Diabetes. 2003; 111(7):405-414.

28. Dornhorst A. Insulinotropic meglitinide analogues. Lancet. 2001; 358(9294):1709-1716.

29. Hatorp V. Clinical pharmacokinetics and pharmacodynamics of repaglinide. Clin Pharmacokinet. 2002; 41(7):471-483

30. Marbury TC, Ruckle JL, Hatorp V, Andersen MP, Nielsen KK, Huang WC, et al. Pharmacokinetics of repaglinide in subjects with renal impairment. Clin Pharmacol Ther. 2000; 67(1):7-15.

31. Schumacher S, Abbasil,Weise D, Hatorp V, SattlerK, SieberJ, et al. Single- and multiple-dose pharmacokinetics of repaglinide in patients with type 2 diabetes and renal impairment. Eur J Clin Pharmacol. 2001; 57(2):147-152.

32. Hasslacher C. Safety and efficacy of repaglinide in type 2 diabetic patients with and without impaired renal function. Diabetes Care. 2003; 26(3):886-891

33. Weaver ML, Orwig BA, Rodriguez LC, Graham ED, Chin JA, Shapiro MJ, et al. Pharmacokinetics and metabolism of nateglinide in humans. Drug Metab Dispos. 2001; 29(4 Pt 1):415-421.

34. Devineni D, Walter YH, Smith HT, Lee JS, Prasad P, McLeod JF. Pharmacokinetics of nateglinide in renally impaired diabetic patients. J Clin Pharmacol. 2003; 43(2):163-170.

35. Inoue T, Shibahara N, Miyagawa K, Itahana R, Izumi M, Nakanishi T, et al. Pharmacokinetics of nateglinide and its metabolites in subjects with type 2 diabetes mellitus and renal failure. Clin Nephrol. 2003; 60(2):90-95.

36. Nagai T, Imamura M, Iizuka K, Mori M. Hypoglycemia due to nateglinide administration in diabetic patient with chronic renal failure. Diabetes Res Clin Pract. 2003; 59(3):191-194.

37. Budde K, Neumayer HH, Fritsche L, Sulowicz W, Stompor T, Eckland D. The pharmacokinetics of pioglitazone in patients with impaired renal function. Br J Clin Pharmacol. 2003; 55(4):368-374.

38. Hollenberg NK. Considerations for management of fluid dynamic issues associated with thiazolidinediones. Am J Med. 2003; 115 Suppl 8A:111S-115S.

39. Nesto RW, Bell D, Bonow RO, Fonseca V, Grundy SM, Horton ES, et 
al. Thiazolidinedione use, fluid retention, and congestive heart failure: a consensus statement from the American Heart Association and American Diabetes Association. October 7, 2003. Circulation. 2003; 108(23):2941-2948.

40. Linnebjerg H, Kothare PA, Park S, Mace K, Reddy S, Mitchell M, et al Effect of renal impairment on the pharmacokinetics of exenatide. Br J Clin Pharmacol 2007; 64(3): 317-327. doi: 10.1111/j.13652125.2007.02890.x.

41. Copley K, McCowen K, Hiles R, Nielsen LL, Young A, Parkes DG. Investigation of exenatide elimination and its in vivo and in vitro degradation. Curr Drug Metab. 2006; 7(4):367-374.

42. Buse JB, Rosenstock J, Sesti G, Schmidt WE, Montanya E, Brett JH, et al. Liraglutide once a day versus exenatide twice a day for type 2 diabetes: a 26-week randomised, parallel-group, multinational, openlabel trial (LEAD-6). Lancet. 2009; 374(9683):39-47. doi: 10.1016/ S0140-6736(09)60659-0.

43. Elbrond B, Jakobsen G, Larsen S, Agerso H, Jensen LB, Rolan P, et al. Pharmacokinetics, pharmacodynamics, safety, and tolerability of a single-dose of NN2211, a long-acting glucagon-like peptide 1 derivative, in healthy male subjects. Diabetes Care. 2002; 25(8):13981404.

44. Davidson JA, Brett J, Falahati A, Scott D. Mild renal impairment and the efficacy and safety of liraglutide. Endocr Pract. 2011; 17(3):345-355. doi: 10.4158/EP10215.

45. Herman GA, Stevens C, Van Dyck K, Bergman A, Yi B, De Smet M, et al: Pharmacokinetics and pharmacodynamics of sitagliptin, an inhibitor of dipeptidyl peptidase IV, in healthy subjects: results from two randomized, double-blind, placebo-controlled studies with single oral doses. Clin Pharmacol Ther. 2005; 78(6):675-688.

46. Bergman AJ, Cote J, Yi B, Marbury T, Swan SK, Smith W, et al. Effect of renal insufficiency on the pharmacokinetics of sitagliptin, a dipeptidyl peptidase-4 inhibitor. Diabetes Care. 2007; 30(7):1862-1864.

47. Chan JC, Scott R, Arjona Ferreira JC, Sheng D, Gonzalez E, Davies MJ, et al. Safety and efficacy of sitagliptin in patients with type 2 diabetes and chronic renal insufficiency. Diabetes Obes Metab. 2008; 10(7):545555. doi: 10.1111/j.1463-1326.2008.00914.x.

48. Fura A, Khanna A, Vyas V, Koplowitz B, Chang SY, Caporuscio C, et al Pharmacokinetics of the dipeptidyl peptidase 4 inhibitor saxagliptin in rats, dogs, and monkeys and clinical projections. Drug Metab Dispos. 2009; 37(6):1164-1171. doi: 10.1124/dmd.108.026088.

49. Brown NJ, Byiers S, Carr D, Maldonado M, Warner BA. Dipeptidy peptidase-IV inhibitor use associated with increased risk of ACE inhibitor associated angioedema. Hypertension. 2009; 54(3):516-523. doi: 10.1161/HYPERTENSIONAHA.109.134197.

50.Grouzmann E, Livio F, Buclin T. Angiotensin-converting enzyme and dipeptidyl peptidase IV inhibitors. An increased risk of angioedema. Hypertension 2009; 54: 468-470. doi: 10.1161/ HYPERTENSIONAHA.109.135244.

51. Lukashevich V, Schweizer A, Shao Q, Groop PH, Kothny W. Safety and efficacy of vildagliptin versus placebo in patients with type 2 diabetes and moderate or severe renal impairment: a prospective 24-week randomized placebo-controlled trial. Diabetes Obes Metab. 2011; 13(10):947-954. doi: 10.1111/j.1463-1326.2011.01467.x.

52. Graefe-Mody U, Friedrich C, Port A, Ring A, Retlich S, Heise T, et al. Effect of renal impairment on the pharmacokinetics of the dipeptidyl peptidase-4 inhibitor linagliptin(*). Diabetes Obes Metab. 2011; 13(10):939-946. doi: 10.1111/j.1463-1326.2011.01458.x.
53. Rabkin R, Ryan MP, Duckworth WC. The renal metabolism of insulin. Diabetologia. 1984; 27(3):351-357.

54. Rubenstein $\mathrm{AH}$, Mako ME, Horwitz DL. Insulin and the kidney. Nephron. 1975; 15(3-5):306-326.

55. Rave K, Heise T, Pfutzner A, Heinemann L, Sawicki PT. Impact of diabetic nephropathy on pharmacodynamic and pharmacokinetic properties of insulin in type 1 diabetic patients. Diabetes Care. 2001; 24(5):886-890.

56. Biesenbach G, Raml A, Schmekal B, Eichbauer-Sturm G. Decreased insulin requirement in relation to GFR in nephropathic Type 1 and insulin-treated Type 2 diabetic patients. Diabet Med. 2003; 20(8):642645.

57. Mak RH. Impact of end-stage renal disease and dialysis on glycemic control. Semin Dial. 2000; 13(1):4-8.

58. Lubowsky ND, Siegel R, Pittas AG. Management of glycemia in patients with diabetes mellitus and CKD. Am J Kidney Dis. 2007; 50(5):865879 .

59. Sica DA, Gehr TW. Diuretic use in stage 5 chronic kidney disease and end-stage renal disease. Curr Opin Nephrol Hypertens. 2003; 12(5):483-490.

60. Kidney Disease Outcomes Quality Initiative (K/DOQI). K/DOQI clinical practice guidelines on hypertension and antihypertensive agents in chronic kidney disease. Am J Kidney Dis. 2004; 43(5 Suppl 1):S1-290.

61. Sica DA. Eplerenone: A New Aldosterone Receptor Antagonist: Are the FDA's Restrictions Appropriate? The Journal of Clinical Hypertension. 2002; 4(6): 441-445. DOI: 10.1111/j.1524-6175.2002.01510.x.

62. Black HR, Sollins JS, Garofalo JL. The addition of doxazosin to the therapeutic regimen of hypertensive patients inadequately controlled with other antihypertensive medications: a randomized, placebocontrolled study. Am J Hypertens. 2000; 13(5 Pt 1):468-474.

63. Bryson CL, Psaty BM. A Review of the Adverse Effects of Peripheral Alpha-1 Antagonists in Hypertension Therapy. Curr Control Trials Cardiovasc Med. 2002; 3(1):7.

64. Lowenthal DT, Affrime MB, Meyer A, Kim KE, Falkner B, Sharif K. Pharmacokinetics and pharmacodynamics of clonidine in varying states of renal function. Chest. 1983; 83(2 Suppl):386-390.

65. Frishman WH, Alwarshetty M. Beta-adrenergic blockers in systemic hypertension: pharmacokinetic considerations related to the current guidelines. Clin Pharmacokinet 2002; 41(7): 505-516.

66. McCullough PA, Sandberg KR, Borzak S, Hudson MP, Garg M, Manley $\mathrm{HJ}$. Benefits of aspirin and beta-blockade after myocardial infarction in patients with chronic kidney disease. Am Heart J. 2002; 144(2):226232.

67. Bakris GL. Role for beta-blockers in the management of diabetic kidney disease. Am J Hypertens. 2003; 16(9 Pt 2):7S-12S.

68. Sica DA, Gehr TW. Calcium-channel blockers and end stage renal disease: pharmacokinetic and pharmacodynamic considerations. Curr Opin Nephrol Hypertens. 2003; 12(2):123-131.

69. Chrysant SG, Chrysant C, Trus J, Hitchcock A. Antihypertensive effectiveness of amlodipine in combination with hydrochlorothiazide. Am J Hypertens. 1989; 2(7):537-541.

70. Bakris GL, Weir MR, Secic M, Campbell B, Weis-McNulty A. Differential effects of calcium antagonist subclasses on markers of nephropathy progression. Kidney Int. 2004; 65(6):1991-2002.

71. Bakris GL, Weir MR, Shanifar S, Zhang Z, Douglas J, van Dijk DJ, 
et al. Effects of blood pressure level on progression of diabetic nephropathy: results from the RENAAL study. Arch Intern Med. 2003; 163(13):1555-1565.

72. Sica DA. Calcium channel blocker-related peripheral edema: can it be resolved? J Clin Hypertens (Greenwich). 2003; 5(4):291-4, 297.

73. Sica DA. Drug dosing in renal disease. In Bakris G, ed. The Kidney and Hypertension. 1st ed. Martin Dunitz, London. 2003. p. 127-138.

74. Bakris GL, Weir MR. Angiotensin-converting enzyme inhibitorassociated elevations in serum creatinine: is this a cause for concern? Arch Intern Med 2000; 160(5): 685-693.

75. Sica DA. Renal handling of angiotensin receptor blockers: clinical relevance. Curr Hypertens Rep. 2003; 5(4):337-339.

76. Schoolwerth AC, Sica DA, Ballermann BJ, Wilcox CS. Rena considerations in angiotensin converting enzyme inhibitor therapy: a statement for healthcare professionals from the Council on the Kidney in Cardiovascular Disease and the Council for High Blood Pressure Research of the American Heart Association. Circulation. 2001; 104(16):1985-1991.

77. Catapano AL, Reiner Z, De Backer G, Graham I, Taskinen MR, Wiklund 0 , et al. ESC/EAS Guidelines for the management of dyslipidaemias The Task Force for the management of dyslipidaemias of the European Society of Cardiology (ESC) and the European Atherosclerosis Society (EAS). Atherosclerosis. 2011; 217(1):3-46.

78. Launay-Vacher V, Izzedine H, Deray G. Statins' dosage in patients with renal failure and cyclosporine drug-drug interactions in transplant recipient patients. Int J Cardiol. 2005; 101(1):9-17.

79. Tonelli M, Isles C, Craven T, Tonkin A, Pfeffer MA, Shepherd J, et al. Effect of pravastatin on rate of kidney function loss in people with or at risk for coronary disease. Circulation. 2005; 112(2):171-178.
80. Baigent C, Landray M, Leaper C, Altmann P, Armitage J, Baxter A, et al. First United Kingdom Heart and Renal Protection (UK-HARP-I) study: biochemical efficacy and safety of simvastatin and safety of low-dose aspirin in chronic kidney disease. Am J Kidney Dis. 2005; 45(3):473484

81. Collins R, Armitage J, Parish S, Sleigh P, Peto R. MRC/BHF Heart Protection Study of cholesterol-lowering with simvastatin in 5963 people with diabetes. A randomized placebo-controlled trial. Lancet. 2003; 361(9374):2005-2016.

82. Kosoglou T, Statkevich P, Johnson-Levonas AO, Paolini JF, Bergman AJ, Alton KB: Ezetimibe. A review of its metabolism, pharmacokinetics and drug interactions. Clin Pharmacokinet. 2005; 44(5):467-494.

83. Landray M, Baigent C, Leaper C, Adu D, Altmann P, Armitage J, et al. The Second United Kingdom Heart and Renal Protection (UK-HARPII) Study: A randomized controlled study of the biochemical safety and efficacy of adding ezetimibe to simvastatin as initial therapy among patients with CKD. Am J Kidney Dis. 2006; 47(3): 385-395.

84. Kidney Disease Outcomes Quality Initiative (K/DOQI) Group. K/DOQI clinical practice guidelines for managing dyslipidemias in chronic kidney disease. 2003 Apr;41(4 Suppl 3):I-IV, S1-91.

85. Farbakhsh K, Kasiske BL. Dyslipidemias in patients who have chronic kidney disease. Med Clin North Am. 2005; 89(3):689-699.

86. Chan MK. Gemfibrozil improves abnormalities of lipid metabolism in patients on continuous ambulatory peritoneal dialysis: The role of postheparin lipases in the metabolism of high-density lipoprotein subfractions. Metabolism. 1989; 38(10):939-945.

87. Ballantyne CM, Corsini A, Davidson MH, Holdaas H, Jacobson TA, Leitersdorf E, et al. Risk for myopathy with statin therapy in high-risk patients. Arch Intern Med. 2003; 163(5):553-564. 